\title{
Influência do diâmetro de estacas no enraizamento de Tecoma stans (L.) Juss. ex Kunth
}

\author{
Cutting diameter influence in the rooting of \\ Tecoma stans (L.) Juss. ex Kunth
}

\author{
Daniela Biondi ${ }^{*}$; Edgard Alfredo Bredow ${ }^{2}$; Luciana Leal ${ }^{3}$
}

\section{Resumo}

Tecoma stans (L.) Juss. ex Kunth (Bignoniaceae), árvore nativa das Américas e Antilhas, foi introduzida no Brasil para fins ornamentais e tornou-se uma espécie invasora de áreas degradadas e pastagens na região sul. No Estado do Paraná é considerada uma planta invasora nociva, proibida a sua entrada, o plantio, o transporte, a produção e o comércio de mudas, sementes, pedaços de caules e raízes. O trabalho teve como objetivo comprovar o potencial de enraizamento de estacas caulinares lenhosas de Tecoma stans com diferentes diâmetros de espessura. $\mathrm{O}$ delineamento utilizado foi inteiramente casualizado com três tratamentos: $\mathrm{T} 1=$ diâmetro da estaca de $0,60-0,80 \mathrm{~cm}$; T2 = diâmetro da estaca de $0,81-1,00$ $\mathrm{cm}$ e T3 = diâmetro da estaca de 1,01-1,20 cm. As variáveis analisadas foram: percentagem de estacas enraizadas, número de brotações por estaca, comprimento das brotações $(\mathrm{cm})$, percentagem de estacas com presença de mais de 10 raízes e comprimento das 3 maiores raízes por estaca $(\mathrm{cm})$. Todas as estacas apresentaram $100 \%$ de enraizamento. Os tratamentos T2 e T3 diferiram estatisticamente do tratamento T1 para o comprimento das brotações, enquanto o T2 diferiu dos demais para o comprimento das raízes. A facilidade desta espécie em propagar-se vegetativamente reforça e comprova a sua característica invasora. Palavras-chave: Amarelinho, estaquia caulinar, estaca lenhosa, espécie invasora

\begin{abstract}
Tecoma stans (L.) Juss. ex Kunth (Bignoniaceae) is a native tree from the Americas and Antilles and was introduced in Brazil for ornamental reasons, but became an invasive species in degraded areas and pastures in the south region. In Paraná State it is considered a noxious invasive species and its entrance, planting, transport, production and the commerce of its seedlings, seeds, pieces of stem and roots are forbidden. The aim of this research was to prove the rooting ability potential of hardwoody stem cuttings of Tecoma stans with different diameter thickness. The experiment was conducted in a completely randomized design with three treatments: $\mathrm{T} 1=$ stem diameter from $0.60-0.80 \mathrm{~cm}, \mathrm{~T} 2=$ stem diameter from $0.81-1.00 \mathrm{~cm}$ and $\mathrm{T} 3=$ stem diameter from $1.01-1.20 \mathrm{~cm}$. The evaluated variables were: rooting rate, the number of sprouting per cutting, length of sprouting per cutting $(\mathrm{cm})$, cutting rate with more than ten roots and length of the three larger roots formed per cutting $(\mathrm{cm})$. All the cuttings showed $100 \%$ of rooting. The T2 and T3 treatments differed statistically from $\mathrm{T} 1$ treatment for sprouting length, while T2 differed from the others, for the roots length. The easiness of this species to propagate in a vegetative way reinforces and proves its invasive characteristics.

Key words: Amarelinho, stem cutting, hardwoody cuttings, invasive species
\end{abstract}

\footnotetext{
${ }_{1}$ Eng. Florestal, Dra., Departamento de Ciências Florestais - UFPR, pesquisadora bolsista do CNPq - dbiondi@ufpr.br.

2 Eng. Florestal, Mestre em Ciências do Solo - UFPR - bredowe@terra.com.br.

3 Eng. Florestal, Mestre em Ciências Florestais - UFPR - luciana_paisagem@yahoo.com.br

* Autor para correspondência
}

Recebido para publicação 24/04/07 Aprovado em 04/12/07 


\section{Introdução}

A espécie Tecoma stans (L.) Juss. ex Kunth (Bignoniaceae), conhecida vulgarmente como amarelinho, ipê-mirim ou ipêzinho-de-jardim, é uma árvore ornamental de cinco a sete metros de altura, nativa das Américas e Antilhas. É adequada para o plantio em parques e jardins e é também uma espécie subespontânea em algumas regiões do país, onde é considerada planta daninha de pastagem (LORENZI et al., 2003). No Brasil, foi introduzida para fins ornamentais, mas tornou-se uma espécie invasora de áreas degradadas e pastagens na região sul (ZILLER; ZENNI; GRAF NETO, 2004).

Tecoma stans apresenta rápida disseminação espontânea e sem controle em algumas regiões no Estado do Paraná. Devido a sua potencialidade como planta invasora vem causando problemas em áreas de agricultura e pastagem. Inicialmente encontrada como planta ornamental em logradouros públicos, atualmente vem ocupando matas ciliares, fundo de vales, terrenos baldios e margens de rodovias. Neste Estado é encontrada como espécie ornamental em mais de 80 municípios, como espontânea em margens de rodovias em mais de 130 municípios e invasora de pastagens em mais de 80 municípios, numa área de 50 mil hectares, dos quais 10 mil encontram-se com a capacidade de produção de forragem próxima de zero (KRANZ; PASSINI, 1997; RENÓ, 2002, 2004).

O Estado do Paraná, por meio da Secretaria da Agricultura e do Abastecimento - SEAB, vem tomando medidas de prevenção em relação à invasão do Tecoma stans, através do da resolução $\mathrm{n}^{\circ} 151$ de dezembro de 1997, baseada na Lei $n^{\circ} 11200 / 95$ e Decreto Regulamentador 3287/97 que resolve: Artigo $1^{0}$ - Considerar a planta Tecoma stans, como invasora nociva proibida no Estado; Artigo $2^{0}-$ Proibir no Estado, a entrada, o plantio, o transporte, a produção e o comércio de mudas, sementes, pedaços de caules e raízes (RENÓ, 2004; INSTITUTO AGRONÔMICO DO PARANÁ, 2007).
No Paraná, esta espécie vegeta praticamente todo $\mathrm{o}$ ano e floresce principalmente em agosto e setembro (INSTITUTO AGRONÔMICO DO PARANÁ, 2007). Esta espécie produz anualmente grande quantidade de sementes, facilitando sua multiplicação. Mudas espontâneas são encontradas nas proximidades de plantas adultas (LORENZI et al., 2003). Sua reprodução se dá por sementes e por pedaços de caules e raízes, apresentando crescimento vigoroso e brotação rápida e intensa. Sua dispersão dá-se através do vento, da água e do homem (RENÓ, 2004).

Uma característica comum a muitas espécies exóticas invasoras é a sua elevada fertilidade quando comparadas com as espécies nativas das comunidades invadidas devido, em parte, à ausência de inimigos naturais. Estas espécies apresentam também, frequentemente, reprodução vegetativa, essencial para a sua fixação e dispersão a curtas distâncias. São ainda caracterizadas por mecanismos de dispersão eficazes a longas distâncias, o que sugere que podem expandir-se mais rapidamente, e são menos influenciadas pela perda de habitats. Outra característica comum a várias espécies invasoras, é a grande longevidade das suas sementes no solo, formando bancos de sementes mais numerosos e viáveis do que muitas das espécies nativas (MARCHANTE, 2007).

As únicas informações sobre a reprodução assexuada de Tecoma stans disponíveis foram obtidas de observações de campo. A partir dessas observações, constatou-se a necessidade de estabelecer um delineamento experimental para avaliar estatisticamente o potencial de enraizamento de estacas caulinares lenhosas de Tecoma stans com diferentes diâmetros de espessura.

\section{Material e Métodos}

O material utilizado para o experimento foi proveniente de brotações de uma árvore de Tecoma stans com idade aproximada de sete anos, localizada 
no Sítio das Pedras no município de Londrina - PR, com coordenadas de $23^{\circ} 22^{\prime} 17^{\prime \prime} \mathrm{S}$ e $51^{\circ} 05^{\prime} 59^{\prime \prime} \mathrm{W}$ e altitude de $600 \mathrm{~m}$.

O experimento foi realizado no Campus III da Universidade Federal do Paraná, na cidade de Curitiba -PR, com longitude $49^{\circ} 16^{\prime} 23^{\prime \prime} \mathrm{W}$ e latitude $25^{\circ} 25^{\prime} 40^{\prime \prime} \mathrm{S}$ e altitude $980 \mathrm{~m}$. O clima é do tipo $\mathrm{Cfb}$, segundo a classificação de Köppen, com clima temperado (ou subtropical) úmido, mesotérmico, sem estação seca e com verões frescos. A temperatura média no verão é de $20,94^{\circ} \mathrm{C}$, a precipitação média anual é de 1563,30 mm e a umidade média relativa do ar é de $80,81 \%$ (INSTITUTO DE PESQUISA E PLANEJAMENTO URBANO DE CURITIBA, 2006).

Foram utilizadas estacas caulinares lenhosas sem folhas que, segundo Kämpf(2000a), é o tipo de estaca mais indicada para espécies arbóreas, ornamentais ou frutíferas, caducifólias ou não. $\mathrm{O}$ tamanho das estacas foi de 20 a $30 \mathrm{~cm}$ de comprimento, conforme as recomendações de Browse (1979) e Hartmann et al (2002). Cada estaca apresentava três inserções ou nós. O diâmetro das estacas variou de 0,60 a 1,20 $\mathrm{cm}$. Para o leito de enraizamento foi utilizado o substrato areia lavada que Kämpf (2000b) considera como um dos meios de cultivo mais frequentemente utilizados em viveiros. As estacas foram enterradas na areia a uma profundidade de $10 \mathrm{~cm}$.

$\mathrm{O}$ experimento foi montado num delineamento inteiramente casualizado, onde foram testados três tratamentos conforme o tamanho da estaca: $\mathrm{T} 1=$ diâmetro da estaca de $0,60-0,80 \mathrm{~cm} ; \mathrm{T} 2=$ diâmetro da estaca de $0,81-1,00 \mathrm{~cm}$ e T3 = diâmetro da estaca de 1,01-1,20 cm, com três repetições de 6 estacas cada.

As variáveis analisadas foram: percentagem de estacas enraizadas, número de brotações por estaca, comprimento das brotações $(\mathrm{cm})$, percentagem de estacas com presença de mais de 10 raízes e comprimento das 3 maiores raízes por estaca $(\mathrm{cm})$. A instalação do experimento foi realizada em novembro de 2005 e as avaliações foram feitas em fevereiro de 2006 (aproximadamente 100 dias após o plantio).

Os dados obtidos na avaliação foram comparados estatisticamente entre si por análise de variância e as médias dos tratamentos foram comparadas pelo teste de SNK ao nível de 5\% de significância.

\section{Resultados e Discussão}

Em todos os tratamentos testados, o número de estacas enraizadas foi igual a 100\% (Tabela 1), aproximadamente 100 dias após o plantio. Portanto, não houve diferença significativa entre a percentagem de enraizamento e o diâmetro das estacas. Tofanelli, Rodrigues e Ono (2003) testando o enraizamento de estacas lenhosas de pessegueiro cv. Okinawa constatou que não houve efeito do diâmetro sobre o potencial de enraizamento. Este fato, $100 \%$ de enraizamento em estacas lenhosas, vai de encontro à afirmação de Wendling, Paiva e Gonçalves (2005), dizendo que dentre todos os tipos de estacas caulinares, a herbácea é a que possui maior capacidade de enraizamento. Complementa ainda que, quanto mais herbácea e nova a estaca, maior será sua capacidade de enraizamento.

No âmbito relacionado a plantas invasoras, este resultado (100\% de enraizamento) reforça a facilidade da espécie Tecoma stans de se propagar por meios de pedaços de caules ou galhos, considerados por Renó (2004) e INSTITUTO AGRONÔMICO DO PARANÁ (2007).

Estatisticamente, não houve diferença significativa entre o número de brotações e entre percentagem de estacas com mais de 10 raízes (Tabela 1). Fachinello et al. (1995) atestam que as estacas de maior diâmetro apresentam maiores níveis de reservas que favorecem o enraizamento, mas, por outro lado, podem também apresentar altas taxas de brotações desfavorecendo o enraizamento. 
Tabela 1. Resultados da comparação das médias para as variáveis analisadas em experimento de estaquia de Tecoma stans após 100 dias, Curitiba - PR, 2006

\begin{tabular}{lccccc}
\hline TRATAMENTOS & E.E. $(\%)$ & N.B. & C.B. $(\mathrm{cm})$ & E.M.D.R. $(\%)$ & C.R. $(\mathrm{cm})$ \\
\hline T1 $(0,60-0,80 \mathrm{~cm})$ & $100,00 \mathrm{~A}$ & $2,6 \mathrm{~A}$ & $2,4 \mathrm{~B}$ & $50,00 \mathrm{~A}$ & $15,3 \mathrm{C}$ \\
T2 $(0,81-1,00 \mathrm{~cm})$ & $100,00 \mathrm{~A}$ & $3,0 \mathrm{~A}$ & $5,7 \mathrm{~A}$ & $55,55 \mathrm{~A}$ & $31,7 \mathrm{~A}$ \\
T3 $(1,01 \mathrm{a} 1,20 \mathrm{~cm})$ & $100,00 \mathrm{~A}$ & $3,2 \mathrm{~A}$ & $7,4 \mathrm{~A}$ & $33,33 \mathrm{~A}$ & $28,9 \mathrm{~B}$ \\
\hline Probabilidade & $1,00^{\mathrm{ns}}$ & $0,128^{\text {ns }}$ & $0,024^{*}$ & $0,353^{\mathrm{ns}}$ & $0,036^{* *}$ \\
\hline
\end{tabular}

Médias seguidas de mesma letra na coluna não diferem entre si a 5\% de significância pelo teste SNK.

E.E. $=$ percentagem de estacas enraizadas; N.B. $=$ número de brotações por estaca; C.B. $=$ comprimento das brotações por estaca, E.M.D.R. = percentagem de estacas com mais de 10 raízes, C.R. $=$ comprimento das 3 maiores raízes por estaca.

Apesar de não ter diferença significativa entre os tratamentos, observa-se na Tabela 1 que os tratamentos $\mathrm{T} 1$ e $\mathrm{T} 2$ apresentaram $(\geq 50 \%)$ das estacas com mais de dez raízes (Figura 1). Isto demonstra que as estacas de $0,60 \mathrm{~cm}$ até $1,0 \mathrm{~cm}$ de diâmetro têm melhores condições de produzir um maior número de raízes. Para a sobrevivência de mudas, proveniente de propagação vegetativa, o número de raízes na estaca deve ser mais importante do que o comprimento das raízes porque a área de absorção de água e nutrientes é bem maior. Além disso, estacas com raízes maiores têm mais chance de perda ou danos na transposição de mudas para outro recipiente (processo de repicagem).

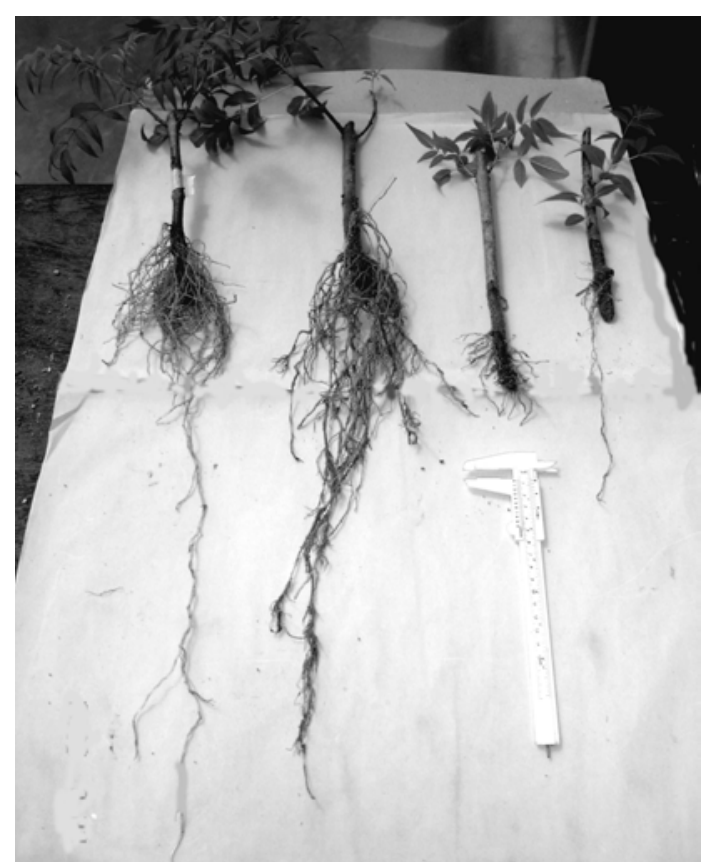

Figura 1. Estacas enraizadas de Tecoma stans após 100 dias no leito de enraizamento
Para a variável comprimento das brotações, os tratamentos T2 e T3 diferiram estatisticamente do tratamento T1 (estaca de menor diâmetro). Renó (2004) observou que estacas de Tecoma stans produziram gemas na região proximal com emergência do broto caulinar aéreo cerca de 60 dias pós-plantio. Diz ainda que este tipo de reprodução vegetativa, comum em estacas caulinares, é importante em várias espécies, incluindo algumas de interesse econômico tais como: cana-de-açúcar, mandioca e amoreira.

Tofanelli, Rodrigues e Ono (2003) pesquisando pessegueiro cv. Okinawa encontrou maior percentual de brotação nas estacas mais espessas, devido talvez pela maior disponibilidade de reservas nas estacas com maior diâmetro, favorecendo a emissão dos brotos.

Hoppe et al. (1999) considerou que o parâmetro diâmetro de estacas influenciou no desenvolvimento em altura das brotações de Platanus $x$ acerifolia e estacas com diâmetros entre 1 e $2 \mathrm{~cm}$ são as mais indicadas para a produção de mudas desta espécie.

Para a variável comprimento das raízes o melhor tratamento foi o T2 (estaca de tamanho médio) diferindo estatisticamente dos demais tratamentos. Renó (2004) afirma que Tecoma stans tem a característica de formar gemas reparativas nas raízes gemíferas (raízes não pré-formadas), provavelmente como uma resposta ao estímulo externo determinado pela luz e temperatura. As raízes gemíferas são caracterizadas como raízes longas, localizadas paralelamente à superfície do solo. Esta espécie 
apresenta a capacidade gemífera em raízes verticais com profundidade de 1,5 $\mathrm{m}$, desde que sejam estimuladas. $\mathrm{E}$ as raízes produzem gemas mesmo quando são destacadas da planta-mãe.

\section{Conclusão}

Com os resultados obtidos foi possível chegar as seguintes conclusões:

a) o enraizamento das estacas de Tecoma stans é facilmente obtido com estacas de 0,60 a $1,20 \mathrm{~cm}$ de diâmetro (100\% de enraizamento);

b) o diâmetro das estacas analisadas $(0,60$ a 1,20 $\mathrm{cm})$ não influenciou o número de brotações e nem a maior percentagem de estacas com mais de 10 raízes, influenciando somente o comprimento de brotações e de raízes;

c) a classe de estacas com diâmetro de 0,81 a 1,00 $\mathrm{cm}$ foi a que apresentou os melhores resultados em comprimento de raízes;

d) comprova-se, portanto, a facilidade da espécie invasora Tecoma stans em propagar-se vegetativamente, salientando assim uma das características essenciais para a sua fixação e dispersão a curtas distâncias.

\section{Referências}

BROWSE, P. M. A. Propagação das plantas: sementes, raízes, bolbos e rizomas, mergulhia, estacas de madeira e foliares, enxertia de borbulha e de cavalo e garfo. 4.ed. Mira-Sintra: Europa-América, 1979.

FACHINELLO, J. C.; HOFFMANN, A.; NACHTIGAL, J. C.; KERS, E.; FORTES, G. R. L. Propagação de plantas frutiferas de clima temperado. Pelotas: UFPEL, 1995.

HARTMANN, H. T.; KESTER, D. E.; DAVIES JÚNIOR, F. T.; GENEVE, R. L. Plant propagation: principles and practices. 7.ed. New Jersey: Prentice Hall, 2002.

HOPPE, J. M.; SCHUMACHER, M. V.; MIOLA, A. C.; OLIVEIRA, L. S. Influência do diâmetro de estacas no desenvolvimento dos brotos de Platanus $x$ acerifolia. Ciência Florestal, Santa Maria, v. 9, n. 1, p. 25-28, 1999.
INSTITUTO AGRONÔMICO DO PARANÁ - IAPAR. Amarelinho: uma planta invasora de pastagem. 2007. Disponível em: <http://www.iapar.br/zip_pdf/ amarelinho.pdf>. Acesso em: 23 fev. 2007.

INSTITUTO DE PESQUISA E PLANEJAMENTO URBANO DE CURITIBA - IPPUC. Curitiba em dados. 2006. Disponível em: <http://ippucnet.ippuc.org.br/ b a n c odedados/curitibaem ados/ curitiba_em_dados_pesquisa.asp >. Acesso em: $23 \mathrm{fev}$. 2007.

KÄMPF, A. N. Propagação. In: Produção comercial de plantas ornamentais. Guaíba: Agropecuária, 2000a. p. 151-170.

. Substrato. In: Produção comercial de plantas ornamentais. Guaíba: Agropecuária, 2000b. p. 4572.

KRANZ, W. M.; PASSINI, T. Amarelinho: biologia e controle. Informe da Pesquisa, Londrina, v. 17, n. 121, p. 1-19, 1997.

LORENZI, H.; SOUZA, H. M.; TORRES, M. A. V.; BACHER, L. B. Árvores exóticas no Brasil: madeireiras, ornamentais e aromáticas. Nova Odessa: Instituto Plantarum, 2003.

MARCHANTE, H. Invasões biológicas: características das espécies invasoras. Disponível em: <http:// www.uc.pt/invasoras/invasoes/caracteristicas.htm>. Acesso em: 7 mar. 2007.

RENÓ, L. R. Propagação vegetativa e fenologia de Tecoma stans (L.) Juss. Ex. Kunth (Bignoniaceae). In: PEDROSAMACEDO, J. H.; BREDOW, E. A. Principio e rudimentos do controle biológico de plantas: coletânea. Curitiba: [s.n.], 2004. p. 107-111.

. Anatomia da raiz e fenologia de Tecoma stans (L.) Kunth (Bignoniaceae). 2002. Dissertação (Mestrado em Agronomia) - Universidade Estadual de Maringá, Maringá.

TOFANELLI, M. B. D.; RODRIGUES, J. D.; ONO, E. O. Enraizamento de estacas lenhosas de pessegueiro cv. Okinawa em diferentes diâmetros de ramos, substratos e recipientes. Ciência Rural, Santa Maria, v. 33, n. 3, p. 437442, 2003.

WENDLING, I.; PAIVA, H. N.; GONÇALVES, W. Técnicas de produção de mudas de plantas ornamentais. Viçosa: Aprenda Fácil, 2005.

ZILLER, R. S.; ZENNI, R. D.; GRAF NETO, J. Invasões biológicas: introdução, impactos e espécies exóticas invasoras no Brasil. In: PEDROSA-MACEDO, J. H.; BREDOW, E. A. Princípios e rudimentos do controle biológico de plantas: coletânea. Curitiba: [s.n.], 2004. p. $17-41$. 
